\title{
CHARACTERISATION OF A NOVEL FRUIT TYPE FOUND IN EHRETIA (EHRETIACEAE, BORAGINALES)
}

\author{
MARC GOTTSCHLING ${ }^{1,2} \&$ HARTMUT H. HILGER ${ }^{1}$
}

\begin{abstract}
SUMMARY
Ehretia (Ehretiaceae, Boraginales) has been divided into two major clades, characterised by fruits with four endocarpids (Ehretia I, including species of Ehretia formerly belonging to Rotula) and by fruits with two endocarpids (Ehretia II, plus E. microphylla (= Carmona retusa) with an undivided endocarp), respectively. Both molecular (ITS1) and morphological data support the recognition of an additional clade, Ehretia III (E. longiflora species group). Its representatives are characterised by four endocarpids (as in Ehretia I), but differ in the presence of distinct lamellae on the abaxial surface of each endocarpid (as in Bourreria, also belonging to Ehretiaceae). However, molecular data suggest a close relationship with Ehretia II. At least three species belong to Ehretia III: Chinese E. longiflora, eastern Indian E. wallichiana, and Indonesian E. javanica.
\end{abstract}

Key words: Ehretia longiflora, anatomy, fruit, ITS1, molecular systematics, phylogeny, phylogeography.

\section{INTRODUCTION}

Ehretiaceae (Boraginales) are pantropical in distribution (with centres of diversity in Central America, Africa, and East Asia) and comprise about 150 species. The plants are usually subshrubs, shrubs, or trees, and otherwise have the typical asterid characters such as tetracyclic, pentamerous flowers with five antesepalous stamens and bicarpellate gynoecia. Fruit morphology provides a systematically important set of characters in Ehretiaceae (Pitot, 1939a, b; Miller, 1989; Verdcourt, 1991; Gottschling \& Hilger, 2001). Most of the species of Ehretiaceae have drupes (otherwise dry nutlets), with either undivided, two-, or four-parted endocarps. The individual parts of the two- and four-parted endocarps are termed endocarpids and enclose two seeds or one seed each, respectively. Undivided endocarps contain four seeds. A preliminary phylogenetic analysis (combining both molecular and morphological data) of the core representatives of Ehretiaceae, Ehretia P.Br. and Bourreria P.Br., with a discussion on character evolution, is given in Gottschling \& Hilger (2001).

Ehretia comprises approximately 50 species that are distributed pantropically (Miller, 1989). Based on molecular data (Gottschling \& Hilger, 2001; Hilger \& Gottschling, in prep.), Ehretia is monophyletic and comprises two major clades. Representatives of

1) FU Berlin, Institut für Biologie - Systematische Botanik und Pflanzengeographie, Altensteinstraße 6,D-14195Berlin, Germany; e-mail: caix@zedat.fu-berlin.de (M.Gottschling), hahilger@ zedat.fu-berlin.de (H.H. Hilger).

2) Current address: FU Berlin, Institut für Geologische Wissenschaften - Fachrichtung Paläontologie, Malteserstraße 74-100, D-12249 Berlin, Germany. 
Ehretia I (including species of Ehretia formerly separated as Rotula Lour.) have drupes with a four-parted endocarp (ancestral condition) and have a Gondwanan distribution (Africa, India, Australia). Representatives of Ehretia II have drupes with a two-parted endocarp (with the only exception of E. latifolia DC. with an undivided endocarp), which takes place by a fusion of endocarpids of different carpels ('syn-mericarpy', derived condition: Hilger, 1992; Gottschling \& Hilger, 2001). Ehretia II is distributed both on Gondwanan and on Laurasian continents (North America, East Asia, Australia). Finally, E. microphylla Lam. (= Carmona retusa (Vahl) Masamune, see Hilger \& Gottschling, 2003) with an undivided endocarp is the sisterspecies of Ehretia II (Gottschling \& Hilger, 2001).

The other large taxon of Ehretiaceae, Bourreria, comprises species which are superficially similar to Ehretia, and nomenclature is difficult because early authors did not understand relationships. However, Bourreria can easily be distinguished from Ehretia by apomorphic features, namely distinct lamellae on the abaxial surface of the endocarpids (not known elsewhere in Ehretiaceae so far), each with an additional chamber enclosing the placenta (unique in Ehretiaceae: Thulin, 1987; Verdcourt, 1991; Gottschling \& Hilger, 2001).

In this study, we describe a novel fruit type found in some species of Ehretia, namely E. longiflora Champ. ex Benth. and its relatives, which are distributed in eastern Asia and Polynesia. The systematic position of this species group (here named as Ehretia III) is inferred from molecular data of the First Internal Transcribed Spacer (ITS1) as well as morphological features, which now include a comprehensive survey of all fruit types found in Ehretia. The phylogenetic analysis supports a modified scenario for character evolution in Ehretia as proposed in Gottschling \& Hilger (2001).

It is difficult to calculate how many, and which, species belong to the Ehretia III clade. Intraspecific variability, especially of vegetative traits, is known to be high in Ehretiaceae (e.g., Miller, 1989). Nevertheless, many Ehretia species have been solely described on the basis of weak characters such as (highly homoplastic) leaf size and shape, without consideration of the partition of the endocarp.

Based on the distinctive fruit type, which is presented in this study, we include Chinese E. longiflora, east Indian E. wallichiana Hook.f. \& Thomson ex Gamble, and Indonesian E. javanica Blume. Ehretia dunniana Lév., E. pingbianensis Y.L. Liu, and E. psilosiphon R.R. Mill also share this fruit type, but they are all probably best placed in synonymy of one of the species above.

\section{MATERIALS AND METHODS}

For morphological investigation, fruits of E. longiflora (Table 1) were treated with $95 \%[\mathrm{v} / \mathrm{v}]$ sulphuric acid for 15 minutes. After removing the parenchyma, the endocarpids were cleaned in water, dried, and photographed (CTprecisa,Agfa) with a photo macroscope (Leitz).

For light microscopy, AFE (acetic acid-formalin-ethanol) fixed, immature fruits were dehydrated with an ethanol/tertiary butanol series and embedded in Paraplast巴 (Sherwood). Photographs of safranine-astra blue-stained serial sections (10 $\mu \mathrm{m}$, ReichertJung Supercut 2050) were taken with a Leitz Dialux 20 microscope and a Canon EOS D30 digital camera. 
Table 1. Species list. DNA-numbers follow an internal numbering code of the Institut für Biologie - Systematische Botanik und Pflanzengeographie (Freie Univ. Berlin). Abbreviations: B: Herb., Bot. Mus., Berlin-Dahlem; BSB: Herb., Inst. Biol. - Syst. Bot., Freie Univ. Berlin.; E: Herb., Roy. Bot. Gard. Edinburgh; HB: Botanical garden; MO: Herb., Miss. Bot. Gard.; n. ind.: not indicated.

\begin{tabular}{|c|c|c|c|c|}
\hline DNA No. & Species name with author & Collector / Collection & Location (State) & GenBank \\
\hline 573 & $\begin{array}{l}\text { Bourreria petiolaris (Lam.) } \\
\text { Thulin }\end{array}$ & Polhill \& Paulo 713 (B) & Kenya & AF385784 \\
\hline 576 & Bourreria succulenta Jacq. & Gottschling CUB37 (BSB) & Cuba & AF385777 \\
\hline 450 & Bourreria wrightii Alain & $\begin{array}{l}\text { HB Berlin-Dahlem } \\
\text { 260-18-93-10 (B, BSB) }\end{array}$ & Cuba & AF385782 \\
\hline 541 & Cordia sebestena L. & Gottschling CUB48 (BSB) & Cuba & AF385773 \\
\hline 492 & Ehretia acuminata R.Br. & HB Adelaide (BSB) & Australia & AF385798 \\
\hline 493 & $\begin{array}{l}\text { Ehretia anacua (Terán \& } \\
\text { Berl.) I.M. Johnst. }\end{array}$ & HB Adelaide (BSB) & n. ind. & AF385796 \\
\hline 792 & $\begin{array}{c}\text { Ehretia aquatica (Lour.) } \\
\text { Gottschling \& Hilger }\end{array}$ & Jongkind 2517 (MO) & Ghana & AF385791 \\
\hline 416 & Ehretia cymosa Thonn. & De Wilde 4230 (B) & Ethiopia & AY176074 \\
\hline 415 & Ehretia laevis Roxb. & Rechinger 29501 (B) & Pakistan & AF385787 \\
\hline 763 & Ehretia latifolia DC. & HB Buenos Aires (BSB) & n. ind. & AF385797 \\
\hline 863 & $\begin{array}{l}\text { Ehretia longiflora Champ. } \\
\text { ex Benth. }\end{array}$ & HB Taiwan (BSB) & n. ind. & AY331400 \\
\hline 395 & $\begin{array}{l}\text { Ehretia macrophylla Wall. } \\
\text { (as E. dicksoni Hance) }\end{array}$ & HB Berlin-Dahlem (BSB) & n. ind. & AF385801 \\
\hline 406 & Ehretia microphylla Lam. & HB Singapore (BSB) & Singapore & AF385792 \\
\hline 419 & Ehretia obtusifolia A.DC. & Gillett $12583(\mathrm{~B})$ & Kenya & AY331401 \\
\hline 390 & $\begin{array}{l}\text { Ehretia rigida (Thunb.) Druce } \\
\text { (as E. hottentotica } \text { Burch.) }\end{array}$ & Seydel 357 (B) & Namibia & AF385789 \\
\hline 414 & Ehretia saligna $\mathrm{R} . \mathrm{Br}$. & Walter \& Walter s.n. (B) & Australia & AF385786 \\
\hline 439 & Ehretia tinifolia $\mathrm{L}$. & Gottschling CUB52 (BSB) & Cuba & AF385793 \\
\hline 1362 & $\begin{array}{l}\text { Ehretia wallichiana Hook.f. \& } \\
\text { Thomson ex Gamble }\end{array}$ & Grierson \& Long 4539 (E) & Bhutan & AY331402 \\
\hline 914 & Varronia bullata L. & Gottschling CUB40 (BSB) & Cuba & AY176084 \\
\hline
\end{tabular}

For molecular investigation, 14 species of Ehretia, 5 species of Bourreria, and 2 outgroup species of Cordiaceae were investigated (Table 1). DNA extraction, PCR, purification, and sequencing followed standard protocols (Gottschling \& Hilger, 2001). African specimens were identified using Martins (1990) and Verdcourt (1991), Asian species using Johnston (1951), Liu (1980), and Zhu et al. (1996), Indonesian species using Riedl (1997), Australian species using Bentham \& Mueller (1869), and New World species using Leon \& Alain (1957) and Miller (1989).

The sequences were manually aligned based on the secondary structure of the ITS1 transcript (Gottschling et al., 2001) using Se-Al v2.0a72 (Rambaut, 2001). The complete data matrix is available in NEXUS format on request. Phylogenetic calculations were run in PAUP* 4.0b1 (Swofford, 1998) on a MacIntosh computer. Likelihood and parsimony trees were generated using heuristic searches. Bootstrap analyses $($ criterion $=$ parsimony, with full heuristic search: PBS; criterion $=$ distance, with neighbour-joining search and maximum likelihood setting: DBS) were estimated based on 1000 replicates (addseq $=$ random, nreps $=10$ and starting tree obtained by neighbour-joining, respectively). Likelihood settings from the best-fit model were determined using the AIC-criterion in Modeltest 3.06 (Posada \& Crandall, 1998). 


\section{RESULTS}

\section{Molecular data}

The aligned ITS1 data set was 282 bp in length. 82 of these sites (29\%) were parsimony-informative (4.3 per taxon). Figure 1 shows the best likelihood tree $(-\ln =1752.3582)$ calculated with the best-fit model $(\mathrm{GTR}+\mathrm{G}+\mathrm{I}$ model; number of substitution types: 6; number of distinct data patterns under this model: 137) with bootstrap support values (above branches: criterion $=$ parsimony, below branches: criterion $=$ distance $)$.

All ingroup taxa constitute a monophyletic group compared to the outgroup (98 PBS, 100 DBS). In the parsimony tree, Bourreria (100 PBS, 100 DBS) and Ehretia (with low support: 53 PBS, 53 DBS) are sistergroups. In Ehretia, three clades can be distinguished: Ehretia I (plus E. aquatica (Lour.) Gottschling \& Hilger (三Rotula aquatica Lour.), 92 PBS, 94 DBS), Ehretia II (BS under 50; but 75 PBS, 81 DBS when E. microphylla is excluded), and a clade formed by E. longiflora and E. wallichiana (here named Ehretia III, 100 PBS, 100 DBS). Ehretia microphylla appears to be the sisterspecies of the Ehretia II clade, and together they are closely allied to the Ehretia III clade (but bootstrap support under 50).

\section{Morphological data}

Each fruit of E. longiflora (and its allies) contains four endocarpids. On the abaxial surface, each endocarpid bears five lamellae in a somewhat irregular arrangement (Fig. 2). On the adaxial surface, the slit-like aperture of the funicular canal is situated in a median position (black arrow in Fig. 2). The embryo inside the endocarpid is straight and elongated (shallow arrow in Fig. 2, inferred).

Figure 3 to 5 show transverse median sections of the fruit (and the carpels). Within Ehretiaceae, lamellae on the abaxial surface of each endocarpid are found only in Bourreria and in the E. longiflora species group (Fig. 3, 5). One of these lamellae (II, at the carpel border) is remarkably elongated in E. longiflora. Each placenta is protected by an outer wing of each endocarpid, which is more extensive in E. longiflora than in, e.g., Ehretia I.

\section{DISCUSSION}

\section{The molecular tree}

The maximum likelihood tree computed from the molecular data (Fig. 1) yields the same major topology as in Gottschling \& Hilger (2001): Ehretia s.l. and Bourreria are sistergroups with respect to outgroup representatives. Ehretia s.l. segregates into three monophyletic assemblages, Ehretia I, Ehretia II (with E. microphylla as sisterspecies), and, additionally, Ehretia III (represented here by E. longiflora and E. wallichiana).

Ehretia was historically subdivided into three groups: species with four endocarpids (represented by Ehretia I and Ehretia III, paraphyletic), species with two endocarpids (represented by Ehretia II, monophyletic), and E. microphylla with an undivided endocarp (Gürke, 1893). However, since molecular data support the hypothesis that 'four endocarpids' is the ancestral character state in Ehretiaceae (Gottschling \& Hilger, 2001) a close relationship of Ehretia I and Ehretia III cannot be inferred from this plesiomorphy. On the contrary, Ehretia III appears to be closely related to Ehretia II (plus E. microphylla) as discussed below. 


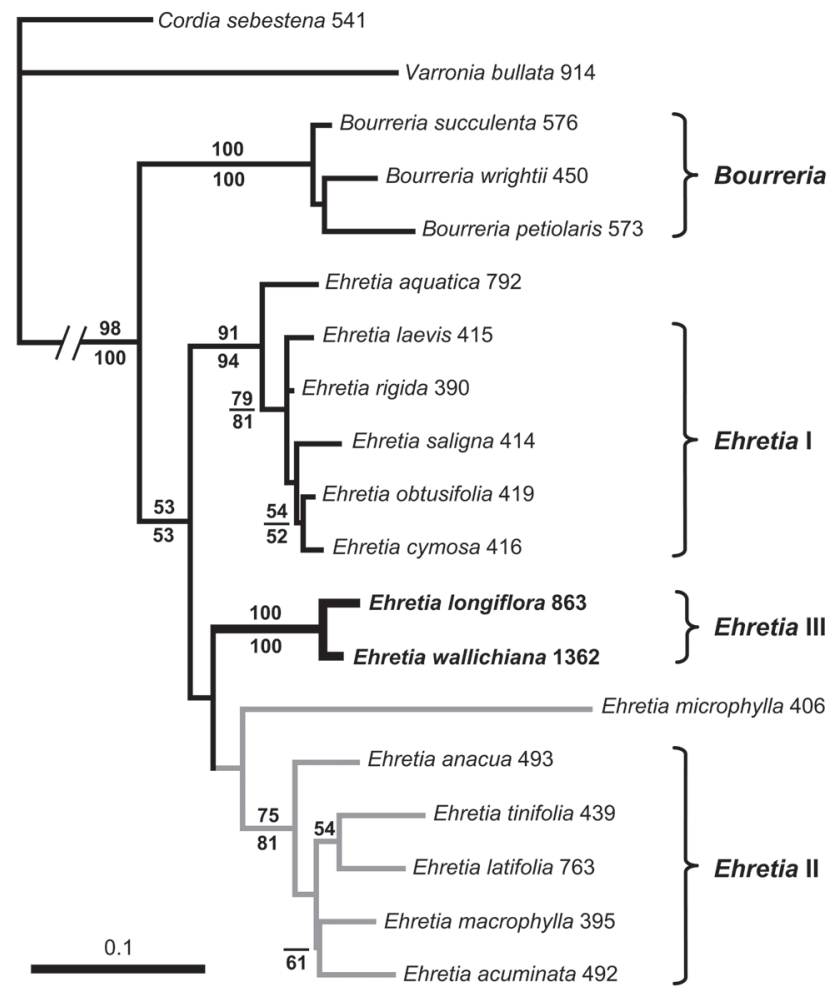

Fig. 1. Maximum likelihood tree of Ehretia based on ITS1 sequences. Important taxa are indicated, branch lengths are to scale. The numbers assigned to the branches are bootstrap support values (values under 50\% not shown); numbers above branches: criterion = parsimony, numbers below branches: criterion = distance. Ingroup taxa with a four-parted endocarp are shown in black, and taxa showing 'syn-mericarpy' (Gottschling \& Hilger, 2001) are grey.

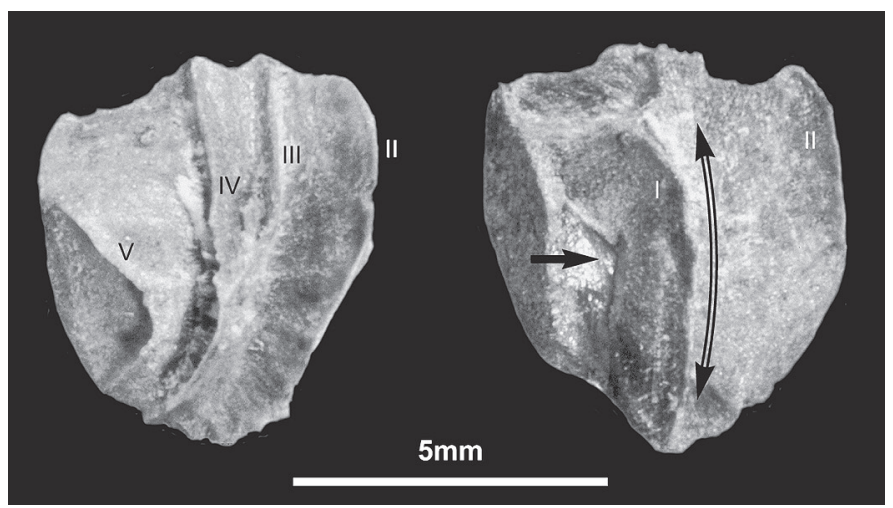

Fig. 2. Endocarpids of Ehretia longiflora, both from the same carpel. Left: abaxial surface with distinct lamellae; right: adaxial surface showing the aperture of funicular canal (black arrow) and the seed with the straight embryo (inferred, hollow arrow). Lamellae I to V are indicated. 


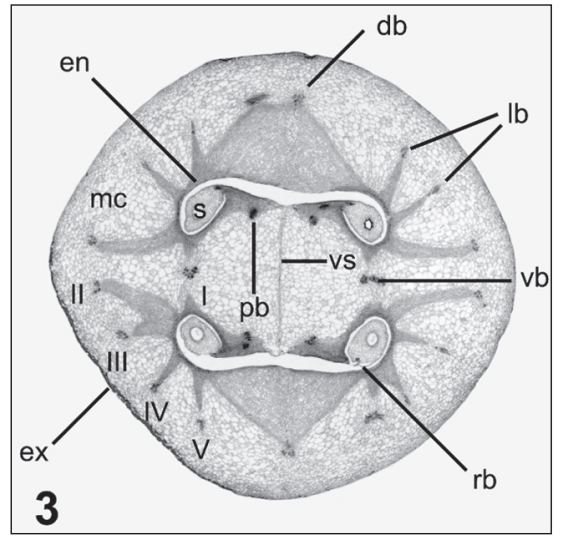

Fig. 3. Transverse section of an immature fruit of Ehretia longiflora (db: dorsal bundle; en: endocarp; ex: exocarp; lb: lateral bundles; mc: mesocarp; pb: placental bundle; rb: raphe bundle; s: seed; vb: ventral bundle; vs: ventral slit). Lamellae I to $\mathrm{V}$ are indicated.

\section{Systematic position of the Ehretia III clade and character polarities}

Monophyly of Ehretia III is supported by both molecular and morphological data. The most striking apomorphy is the very extensive wing of each endocarp that protects the voluminous placenta (Fig. 3, 5). Such a structure is not found elsewhere in Ehretiaceae.

The probable systematic position of the Ehretia III clade can be inferred from morphological features, although molecular data do not provide bootstrap support for it. Two embryo morphologies are found in Ehretia (Gottschling \& Hilger, 2001). In Ehretia I, the embryo is strongly curved, a character that is also found in many other representatives of Ehretiaceae (e.g., Bourreria, Rochefortia Sw.). The straight embryos found in Ehretia II and E. microphylla have been considered as the apomorphic condition. Analogous character polarity is found in Heliotropiaceae (Diane et al., 2002).
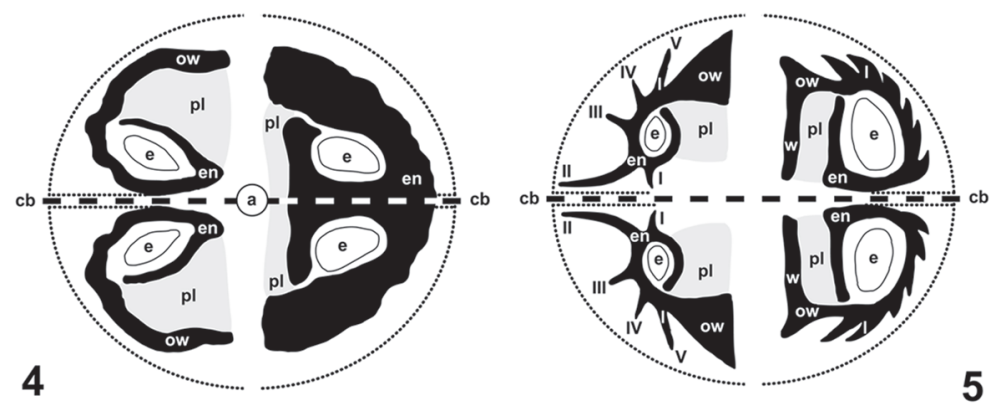

Fig. 4, 5. - Fig. 4. Schematic fruit cross-sections. Left half: Ehretia I with two single endocarpids; right half: Ehretia II with one endocarpid as result of fusion of two endocarpids ('syn-mericarpy': Gottschling \& Hilger, 2001). - Fig. 5. Schematic fruit cross-sections showing representatives of Ehretiaceae with distinct lamellae on the abaxial surface. Left half: Ehretia III (lamellae I to V are indicated); right half: Bourreria (a: shoot axis; cb: carpel border; e: embryo; en: endocarpid; ow: 'outer wing' of endcarpid; pl: placenta). 
The Ehretia III clade has straight embryos (Fig. 2), and this most striking apomorphy argues for the close relationship of Ehretia II (plus E. microphylla) and Ehretia III. This hypothesis is supported by the topology of the maximum likelihood tree, but not by bootstrap analyses.

The well-developed placentas found in Ehretia I (Pitot, 1939b; Gottschling \& Hilger, 2001) as well as in other representatives of Ehretiaceae such as Bourreria and Rochefortia have been considered as homologous (and plesiomorphic) within Ehretiaceae (Fig. 3-5). On the other hand, placentas are only weakly developed in Ehretia II (even shown for the fossil E. clausentia: Gottschling et al., 2002). This has been interpreted as a derived condition in Ehretiaceae. In this regard, Ehretia III, with an extensive placenta, represents the ancestral condition (Fig. 5).

The presence of distinct lamellae on the abaxial surface of each endocarpid have been considered as an exclusive character of Bourreria. They may function as stabilisers of the vascular bundles supplying the mesocarp. However, such lamellae are here also reported for Ehretia III (Fig. 2, 3, 5). Several alternative interpretations are possible, since Ehretia III and Bourreria are only distantly related (Fig. 1): either distinct lamellae on the abaxial surface of each endocarpid developed twice independently in Ehretiaceae (i.e., convergence hypothesis), or distinct lamellae on the abaxial surface were already present in the last common ancestor (of Bourreria and Ehretia) and were independently reduced in Ehretia I and Ehretia II (plus E. microphylla; i.e., symplesiomorphy hypothesis). Finally, lamellae might have been developed in the ancestor of Ehretiaceae, disappeared then in the ancestor of Ehretia, and subsequently reappeared in Ehretia III. The available data are not adequate to resolve this question, since a comprehensive phylogenetic analysis of Ehretiaceae is still wanted.

Phylogeography

Most representatives of Ehretiaceae are distributed on remnants of Gondwana (e.g., Bourreria, Ehretia p.p., Halgania Gaudich., Tiquilia Pers. p.p.), exceptions are found

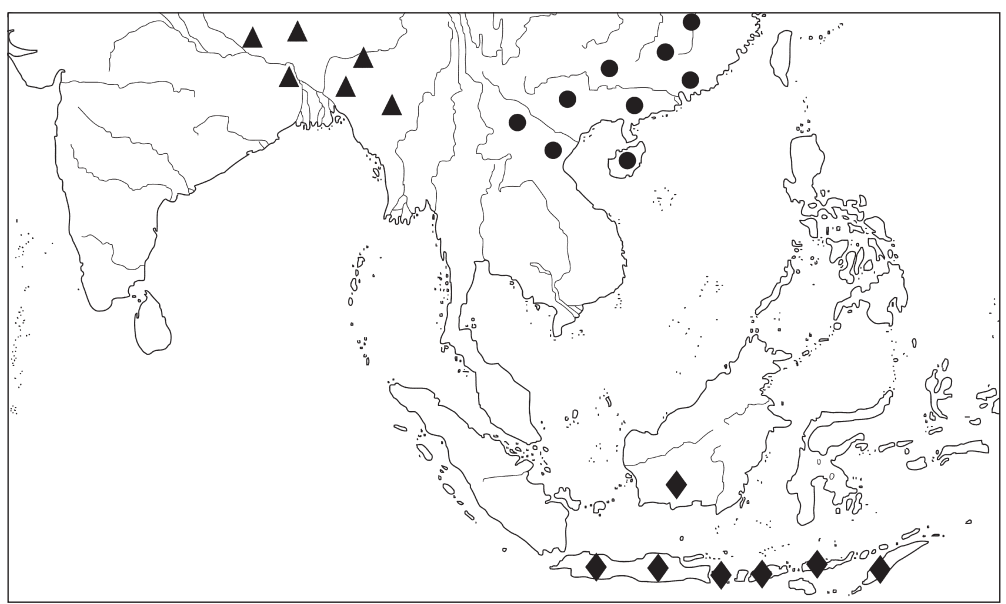

Fig. 6. Current distribution of Ehretia javanica $(\bullet)$, E. longiflora $(\bullet)$, and E. wallichiana $(\mathbf{\Delta})$. 


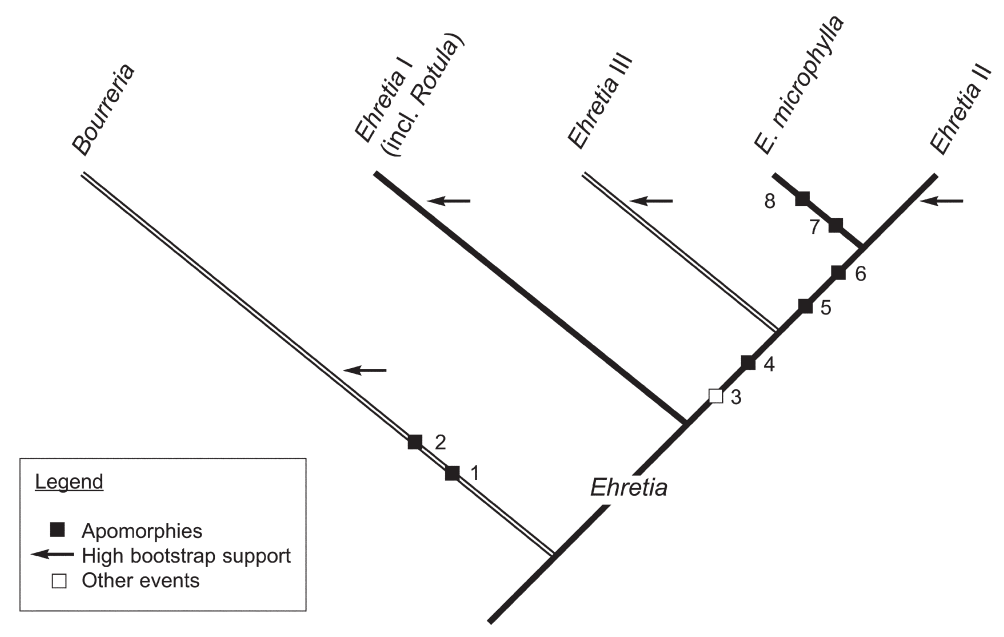

Fig. 7. Annotated phylogram of the taxa under investigation. Symbols see legend. Apomorphies, which are not discussed in this study, are explained in detail in Gottschling (2001) and Gottschling \& Hilger (2001). 1: Transverse wall in each endocarpid forming 2: a chamber filled with placenta; 3: colonisation of Laurasia; 4: embryo straight; 5: aperture of funicular canal in apical position; 6: loss of placenta; 7: endocarp undivided (but anatomically different as in Ehretia latifolia from Ehretia II); 8: 4+4+2 chambers. Taxa with distinct lamellae on the abaxial surface of the endocarpids are double-lined to indicate the convergent development.

in Tiquilia p.p. and Ehretia p.p. The occurrence of predominantly Laurasian taxa in the Ehretiaceae (e.g., Ehretia II, with a disjunction between North America and Eastern Asia) has been discussed as result of individual colonisation events (Gottschling \& Hilger, 2001; Gottschling et al., in press). As an example, the wide distribution of E. acuminata R.Br. (Ehretia II) from continental Asia through Australia can then be easily interpreted as a secondary invasion into Gondwanan continents (i.e., Australia; Johnston, 1951).

The distribution of the Ehretia III species group also appears to be primarily Laurasian (Fig. 6, with E. javanica immigrated from Asia). Based on the monophyly of Ehretia II (plus E. microphylla) and Ehretia III as here discussed, the colonisation of Laurasia is now not assumed for Ehretia II exclusively (Gottschling \& Hilger, 2001), but for the entire group. Subsequently, molecular tree topology suggests Ehretia III and E. microphylla as two relict (and partly sympatric) endemic lineages of this monophyletic group in eastern Asia and adjacent regions.

Figure 7 summarises the results of this study. Morphological apomorphies are indicated together with nodes with high bootstrap support values.

\section{ACKNOWLEDGEMENTS}

We would like to thank Hen-biau King (Taiwan) and the collectors and the curators of the herbaria and botanical gardens (especially from Edinburgh, Adelaide, and Singapore) in the species list for providing us with plant material, Maximilian Weigend (Berlin) and two anonymous reviewers for helpful comments on the text, and Anita Biesek and Carola Müller (both Berlin) for technical work. 


\section{REFERENCES}

Bentham, G. \& F. Mueller. 1869. Flora australiensis 4. Reeve, London.

Diane, N., H. Förther \& H.H. Hilger. 2002. A systematic analysis of Heliotropium, Tournefortia, and allied taxa of the Heliotropiaceae (Boraginales) based on ITS1 sequences and morphological data. Amer. J. Bot. 89: 287-295.

Gottschling, M. 2001. Evolutionäre Interpretationen molekularbiologischer Ergebnisse am Beispiel der Ehretiaceae (Boraginales). Sitzungsber. Ges. Naturf. Freunde Berlin 40: 59-73.

Gottschling, M. \& H.H. Hilger. 2001. Phylogenetic analysis and character evolution of Ehretia and Bourreria (Ehretiaceae, Boraginales) based on ITS1 sequences. Bot. Jahrb. Syst. 123: 249-268.

Gottschling, M., H.H. Hilger, N. Diane \& M. Weigend. In press. Testing hypotheses on disjunctions present in the Primarily Woody Boraginales: Ehretiaceae, Cordiaceae, and Heliotropiaceae, inferred from ITS1 sequence data. Int. J. Plant Sci.

Gottschling, M., H.H. Hilger, M. Wolf \& N. Diane. 2001. Secondary structure of the ITS1 transcript and its application in a reconstruction of the phylogeny of Boraginales. Pl. Biol. 3: 629-636.

Gottschling, M., D.H. Mai \& H.H. Hilger. 2002. The systematic position of Ehretia fossils (Ehretiaceae, Boraginales) from the European Tertiary and implications for character evolution. Rev. Palaeobot. Palynol. 121: 149-156.

Gürke, M. 1893. Borraginaceae. In: A. Engler \& K. Prantl (eds.), Die natürlichen Pflanzenfamilien 4, 3a: 71-131. Engelmann, Leipzig.

Hilger, H.H. 1992. Morphology of Heliotropium (Boraginaceae) dispersal units. Bot. Acta 105: 387-393.

Hilger, H.H. \& M. Gottschling. 2003. Phylogenetic analysis and character evolution of Ehretia and Bourreria (Ehretiaceae, Boraginales) - correction. Bot. Jahrb. Syst. 124: 149-150.

Hilger, H.H. \& M. Gottschling. In prep. Secondary structure of the trnL $\mathrm{LAA}_{\mathrm{UA}}$ (group I) intron and the molecular delimitation of Ehretiaceae (Boraginales). J. Molec. Evol.

Johnston, I.M. 1951. Studies in the Boraginaceae, XX. Representatives of three subfamilies in Eastern Asia. J. Arnold Arbor. 32: 1-26, 99-122.

Leon, H. \& H. Alain. 1957. Flora de Cuba 4. Contr. Ocas. Mus. Hist. Nat. Colegio 'De La Salle' 16.

Liu, Y. 1980. Revision of Ehretia dicksoni Hance specific name in our country. Bull. Bot. Lab. N.E. Forest. Inst., Harbin 9: 69-73.

Martins, E.S. 1990. Boraginaceae. In: E. Launert \& G.V. Pope (eds.), Flora Zambesiaca 7. Flora Zambesiaca Managing Committee, London.

Miller, J.S. 1989. A revision of the New World species of Ehretia. Ann. Missouri Bot. Gard. 76: $1050-1076$.

Pitot, A. 1939a. Le fruit d' 'Ehretia serrata' Roxb. Bull. Soc. Bot. France 86: 310-314.

Pitot, A. 1939b. Le fruit de quelques Ehrétiées. Bull. Soc. Bot. France 86: 325-332.

Posada, D. \& K.A. Crandall. 1998. Modeltest: testing the model of DNA substitution. Bioinformatics 14: 817-818.

Rambaut, A. 2001. Se-Al. Sequence alignment editor v2.0a72. Oxford.

Riedl, H. 1997. Boraginaceae. Flora Malesiana 13: 43-144. RHHB, Leiden.

Swofford, D.L. 1998. PAUP*. Phylogenetic analysis using parsimony *and other methods. Version 4. Sinauer Associates, Sunderland.

Thulin, M. 1987. Bourreria (Boraginaceae) in tropical Africa. Nordic J. Bot. 7: 413-417.

Verdcourt, B. 1991. Boraginaceae. In: R.M. Polhill (ed.), Flora of tropical East Africa. Crown Agents for the Colonies, London.

Zhu, G., H. Riedl \& R. Kamelin. 1996. Boraginaceae. In: Z. Wu \& P.H. Raven (eds.), Flora of China. Missouri Botanical Garden Press, St. Louis. 